\title{
Evaluation of a Model for Brain Bilirubin Uptake in Jaundiced Newborns
}

\author{
CHARLES E AHLFORS AND ANNE E. PARKER \\ California Pacific Medical Center, Department of Pediatrics, Division of Neonatology, San Francisco, \\ California 94118
}

\begin{abstract}
A model for brain bilirubin uptake (BBU) predicts that BBU in jaundiced newborns typically depends on the plasma total bilirubin concentration (TBC) and the bilirubin-albumin dissociation rate constant $\left(\mathrm{k}_{1}\right)$ rather than the unbound bilirubin $\left(\mathrm{B}_{\mathrm{f}}\right)$. The model's validity was tested by 1 ) evaluating its requirement that $k_{3} \gg k_{2}$, where $k_{3}$ and $k_{2}$ are the rate constants for BBU and $\mathrm{B}_{\mathrm{f}}$-albumin association, respectively, and 2) determining whether the calculated BBU is $\leq 5 \%$ of the bilirubin production rate, the approximate BBU expected if brain bilirubin levels are $<1 \%$ of the miscible bilirubin pool as reported in the literature. The model was investigated using peroxidase test measurements of TBC, $\mathrm{B}_{\mathrm{f}}, \mathrm{k}_{1}$, and $\mathrm{k}_{2}$ from 185 jaundiced newborns. Mean $\mathrm{k}_{2}$ was compared with the reported $\mathrm{k}_{3}$ value of $0.08 / \mathrm{s}$. BBU calculated from TBC and $\mathrm{k}_{1}$ was expected to be $\leq 0.005 \mu \mathrm{g} / \mathrm{kg} / \mathrm{s}$ given the reported bilirubin production rate of $0.1 \mu \mathrm{g} / \mathrm{kg} / \mathrm{s}$. BBU calculated using $\mathrm{B}_{\mathrm{f}}$ was also compared with the bilirubin production rate. The mean $\mathrm{k}_{2}$ of $8.9 \mathrm{~L} / \mu \mathrm{mol} / \mathrm{s}$ was greater than $\mathrm{k}_{3}$, and the mean BBU of $0.72 \mu \mathrm{g} / \mathrm{kg} / \mathrm{s}$ exceeded the expected range of $\leq 0.005 \mu \mathrm{g} / \mathrm{kg} / \mathrm{s}$. However, mean BBU using $\mathrm{B}_{\mathrm{f}}(0.00073$ $\mu \mathrm{g} / \mathrm{kg} / \mathrm{s}$ ) was within the expected range. A mathematical model calculating $\mathrm{BBU}$ as a function of $\mathrm{TBC}$ and $\mathrm{k}_{1}$ could not be
\end{abstract}

\section{ABSTRACT}

validated. BBU calculated from $B_{f}$ is consistent with the observation that $<1 \%$ of the miscible bilirubin pool is distributed in the brain. (Pediatr Res 58: 1175-1179, 2005)

Abbreviations
A, plasma albumin concentration
$\boldsymbol{\alpha}$, fraction of the TBC bound $=\left(\mathrm{TBC}-\mathrm{B}_{\mathrm{f}}\right) / \mathrm{TBC}$
$\mathbf{B B U}$, brain bilirubin uptake
$\mathbf{B}_{\mathbf{f}}$, plasma free bilirubin concentration
$\mathbf{B}_{\text {feq }}$, equilibrium concentration of free bilirubin
$\mathbf{B}_{\mathbf{f s s}}$, steady state concentration of free bilirubin
$\mathbf{E}, \mathrm{TBC}$ extraction fraction
HRP, horseradish peroxidase
$\mathbf{k}_{\mathbf{1}}$, bilirubin-albumin dissociation rate constant
$\mathbf{k}_{\mathbf{2}}$, bilirubin-albumin association rate constant
$\mathbf{k}_{\mathbf{3}}$, rate constant for the uptake of $\mathrm{B}_{\mathrm{f}}$ by the brain
$\mathbf{k}_{\mathbf{p}}$, rate constant for the peroxidase catalyzed oxidation of
bilirubin by peroxide
$\boldsymbol{\tau}$, brain capillary transit time
TBC, plasma total bilirubin concentration

The rate of BBU in jaundiced newborns is generally thought to be a function of the plasma non-albumin bound or "free" bilirubin $\left(\mathrm{B}_{\mathrm{f}}\right)$, and current thinking is that this tiny fraction of the TBC is an important indicator of the risk of bilirubin toxicity (1-3). Recent publications by the American Academy of Pediatrics and the National Institutes of Health aimed at improving the clinical management of jaundiced newborns recommend, among other things, more research into the relationship between $\mathrm{B}_{\mathrm{f}}$ and bilirubin toxicity (4-6).

$\mathrm{B}_{\mathrm{f}}$ is a function of the TBC, the fraction $(\alpha)$ of TBC bound $\left[\alpha=\left(\mathrm{TBC}-\mathrm{B}_{\mathrm{f}}\right) / \mathrm{TBC} \approx 1\right.$ at clinically relevant $\left.\mathrm{TBC}\right]$, the albumin concentration (A), and the bilirubin-albumin dissociation and association rate constants, $\mathrm{k}_{1}$ and $\mathrm{k}_{2}$, respectively:

Received April 21, 2005; accepted May 25, 2005.

Correspondence: Charles E. Ahlfors, M.D., PO Box 2904, Vashon, WA 98070; e-mail: Ligand@centurytel.net

DOI: 10.1203/01.pdr.0000185248.43044.cd

$$
B_{f}=\frac{k_{1} \cdot \alpha \cdot T B C}{k_{2} \cdot[A-(\alpha \cdot T B C)]}
$$

Because $\mathrm{B}_{\mathrm{f}}$ is $<0.1 \%$ of plasma bilirubin but only about $90 \%$ of plasma bilirubin may be bound to albumin in adults (7), $A$ in equation 1 may be considered the "average" concentration of all the plasma species reversibly binding bilirubin (e.g., HDL) and $\mathrm{k}_{1}$ and $\mathrm{k}_{2}$ the "average" constants without fundamentally changing the arguments that follow. Several recent studies suggest that $B_{f}$ as measured by the peroxidase test is indeed a more sensitive and specific indicator of bilirubin toxicity than the TBC alone $(3,8-10)$.

Despite these considerations, the clinical management of jaundiced newborns is conventionally based on the less reliable but readily obtainable TBC (4). Although this approach has been questioned (11), there is an often-overlooked but important paper that supports, in theory, the use of the TBC in most clinical situations. About 18 y ago, Robinson and Rapoport applied a general mathematical model they had developed for 
brain uptake of protein bound drugs to $\mathrm{BBU}(12,13)$. Their model predicts that at TBC levels below about $454 \mu \mathrm{M}(27$ $\mathrm{mg} / \mathrm{dL}$ ), the plasma factors determining BBU are TBC and $\mathrm{k}_{1}$. $B_{f}$ becomes important only when the TBC is above $27 \mathrm{mg} / \mathrm{dL}$ or unusual circumstances are present (e.g., drugs that interfere with plasma bilirubin binding). Because $\mathrm{k}_{1}$ is a constant, $\mathrm{BBU}$ will therefore be directly proportional to TBC.

According to their model, as blood enters the cerebral capillaries, $\mathrm{B}_{\mathrm{f}}$ is instantaneously taken up at a rate given by $-\mathrm{k}_{3} \cdot \mathrm{B}_{\mathrm{f}}$, where $\mathrm{k}_{3}$ is the net first order rate constant for brain uptake of bilirubin (they estimate $\mathrm{k}_{3} \approx 0.08 / \mathrm{s}$ ) (13). The instantaneous change in $\mathrm{B}_{\mathrm{f}}$ caused by $-\mathrm{k}_{3} \cdot \mathrm{B}_{\mathrm{f}}$ perturbs the equilibrium $B_{f}\left(B_{\text {feq }}\right)$ at which $d_{\text {feq }} / d t$ is zero per equation 2 below, and $\mathrm{B}_{\text {feq }}$ rapidly falls to the steady state level $\mathrm{B}_{\mathrm{fss}}$, where $\mathrm{dB}_{\mathrm{fss}} / \mathrm{dt}$ remains close to zero (equation 3 ) for the remainder of the trip through the capillaries.

$\frac{d B_{f e q}}{d t}=\left(k_{1} \cdot \alpha \cdot T B C\right)-\left\{k_{2} \cdot[A-(\alpha \cdot T B C)] \cdot B_{f e q}\right\}=0$

$$
\begin{aligned}
& \frac{d B_{f s s}}{d t}=\left(k_{1} \cdot \alpha \cdot T B C\right)-\left\{k_{2} \cdot[A-(\alpha \cdot T B C)] \cdot B_{f s s}\right\} \\
&-\left(k_{3} \cdot B_{f s s}\right) \approx 0
\end{aligned}
$$

Since $\mathrm{dB}_{\mathrm{fss}} / \mathrm{dt} \approx 0$, equation 3 can be rearranged to give:

$$
B_{f s s} \approx \frac{k_{1} \cdot \alpha \cdot T B C}{\left\{k_{2} \cdot[A-(\alpha \cdot T B C)]\right\}+k_{3}}
$$

The general model (12) assumes that the perturbation of equilibrium $\left(-\mathrm{k}_{3} \cdot \mathrm{B}_{\mathrm{eq}}\right)$ is of such magnitude that $\mathrm{B}_{\mathrm{fss}} \ll \mathrm{B}_{\text {feq }}$, generating the inequalities $\mathrm{k}_{2} \cdot[\mathrm{A}-(\alpha \cdot \mathrm{TBC})] \cdot \mathrm{B}_{\mathrm{fss}} \ll<$ $\mathrm{k}_{1} \cdot \alpha \cdot \mathrm{TBC}$ and $\mathrm{k}_{2} \cdot[\mathrm{A}-(\alpha \cdot \mathrm{TBC})] \ll \mathrm{k}_{3}$. Under these circumstances, equation 4 becomes:

$$
B_{f s s} \approx \frac{k_{1} \cdot \alpha \cdot T B C}{k_{3}} .
$$

From equation 5 , it follows directly that $\mathrm{BBU}=\mathrm{k}_{3} \cdot \mathrm{B}_{\mathrm{fss}} \approx$ $\mathrm{k}_{1} \cdot \alpha \cdot \mathrm{TBC}$, the basis of the Robinson and Rapoport model. By combining the capillary transit time, $\alpha(\approx 1), \mathrm{k}_{1}$, and $\mathrm{k}_{3}$ into the constant E (see equation 9 in "Methods"), which is the fraction of the TBC extracted during passage through the capillaries, they obtained equation 6 , which gives $\mathrm{BBU}$ as a function of cerebral blood flow, the constant $\mathrm{E}$, and the TBC $(12,13)$ :

$$
\mathrm{BBU}=\text { cerebral blood flow } \cdot \mathrm{TBC} \cdot \mathrm{E} .
$$

The Robinson and Rapoport model for BBU has never been validated, but it exists in the literature as credible support (assuming little variability in the constants) for using only the $\mathrm{TBC}$, at least when managing jaundiced but otherwise well term newborns whose TBC levels are below $27 \mathrm{mg} / \mathrm{dL}$. In this study, we use measurements of $\mathrm{TBC}, \mathrm{B}_{\mathrm{f}}, \mathrm{k}_{1}$, and $\mathrm{k}_{2}$ from a diverse population of jaundiced newborns to investigate the validity of their model by testing 1) whether $\mathrm{k}_{2} \cdot[\mathrm{A}-$ $(\alpha \cdot \mathrm{TBC})] \ll \mathrm{k}_{3}$ is a valid assumption in the derivation of their model (see equations 4 and 5), and 2) whether BBU calculated by substituting actual $\mathrm{TBC}$ and $\mathrm{k}_{1}$ measurements into equation 6 yields BBU values that are about $5 \%$ of the reported rate of bilirubin production (14), a necessary condition if the BBU is to produce brain bilirubin levels that are $<1 \%$ of the miscible bilirubin pool as reported in the literature $(15,16)$.

\section{METHODS}

Population. We reviewed the medical records of 256 newborns who received plasma TBC and $B_{f}$ measurements as part of their evaluation for newborn jaundice to obtain a set of TBC values and their corresponding $B_{f}, k_{1}$, $\mathrm{k}_{2}$, and albumin concentration for use in the study as outlined below. The review of medical records for this purpose was approved by the California Pacific Medical Center Institutional Review Board.

Hypotheses to Be Evaluated. 1) $\kappa_{2} \ll \kappa_{3}$. Equation 5 depends on the inequality $\mathrm{k}_{2} \cdot[\mathrm{A}-(\alpha \cdot \mathrm{TBC})] \ll \mathrm{k}_{3}$, and Robinson and Rapoport estimate that $\mathrm{k}_{3}$ is about $0.08 / \mathrm{s}(13)$. Inasmuch as $\mathrm{A}-(\alpha \cdot \mathrm{TBC})$ will be numerically greater than 0.08 at all the TBC and albumin levels of the population, $\mathrm{k}_{2} \cdot[\mathrm{A}$ $-(\alpha \cdot \mathrm{TBC})] \lll \mathrm{k}_{3}$ will be true only if $\mathrm{k}_{2} \ll \mathrm{k}_{3}$. We therefore tested the validity of the inequality $\mathrm{k}_{2} \cdot[\mathrm{A}-(\alpha \cdot \mathrm{TBC})] \ll \mathrm{k}_{3}$ by determining whether $\mathrm{k}_{2}$ was substantially less than 0.08 . If the assumption is not valid and the hypothesis rejected, all the mass action factors (TBC, A, $\mathrm{k}_{1}$, and $\mathrm{k}_{2}$ ) are the relevant plasma factors determining $\mathrm{B}_{\mathrm{fss}}$ per equation 4 .

2) $\mathrm{BBU}$ calculated using TBC and $\mathrm{k}_{1}$ (equation 6) will be $\leq 0.005 \mu \mathrm{g} / \mathrm{kg} / \mathrm{s}$. The mean bilirubin production rate reported for well, term newborns is 8.5 $\mathrm{mg} / \mathrm{kg} / 24 \mathrm{~h}$ or $0.10 \mu \mathrm{g} / \mathrm{kg} / \mathrm{s}$ (14). Since it is estimated that $<1 \%$ of the miscible bilirubin pool distributes in the brain $(15,16)$, the model, if valid, should provide rates of BBU somewhere in the neighborhood of $5 \%$ or less $(\leq 0.005$ $\mu \mathrm{g} / \mathrm{kg} / \mathrm{s}$ ) of the bilirubin production rate. For example, assume BBU is $5 \%$ of the bilirubin production rate and that the bilirubin excretion rate is $60 \%$ of the production rate (14). If $10 \%$ of the cardiac output is directed to the brain and $x \mathrm{mg}$ of bilirubin are produced in a period of time, $0.005 x$ will be taken up by the brain and $0.6 x$ will be excreted. Of the $0.4 x$ remaining in the miscible bilirubin pool, $1.25 \%(0.005 / 0.4)$ will reside in the brain.

Measurement of $\boldsymbol{T B C}, \mathrm{B}_{f}, \boldsymbol{k}_{\boldsymbol{1}}$ and $\boldsymbol{k}_{2} . \mathrm{TBC}$ and the $\mathrm{B}_{\mathrm{f}}$ were measured using an FDA-approved peroxidase method (Arrows UB Analyzer, Arrows Co., Ltd., Osaka, Japan) (17). HRP (EC 1.11.17) catalyzed oxidation of $B_{f}$ by peroxide was measured at HRP concentrations of $23.8 \mu \mathrm{g} / \mathrm{mL}(0.54 \mu \mathrm{M})$ and 11.9 $\mu \mathrm{g} / \mathrm{mL}$ to obtain $\mathrm{B}_{\mathrm{f} 1}$ and $\mathrm{B}_{\mathrm{f} 2}$, respectively. Two HRP concentrations are used to avoid underestimating $B_{\text {feq }}$ because, just as $-k_{3} \cdot B_{\text {feq }}$ perturbs $B_{\text {feq }}$ during $\mathrm{BBU}$ (see equations 2 and 3 ), the onset of $\mathrm{B}_{\mathrm{f}}$ oxidation, which is given by $-\mathrm{k}_{\mathrm{p}} \cdot[\mathrm{HRP}] \cdot \mathrm{B}_{\mathrm{feq}}$, where $\mathrm{k}_{\mathrm{p}}$ is the bilirubin oxidation rate constant per unit HRP concentration (18) and [HRP] is the HRP concentration, also perturbs the equilibrium. Substituting $\mathrm{k}_{\mathrm{p}} \cdot[\mathrm{HRP}]$ for $\mathrm{k}_{3}$ in equation 4 gives (19):

$$
B_{f s s}=\frac{k_{1} \cdot \alpha \cdot T B C}{\left\{k_{2} \cdot[A-(\alpha \cdot T B C)]\right\}+\left(k_{p} \cdot[H R P]\right)}
$$

In contrast to the requirement that $\mathrm{k}_{2} \cdot[\mathrm{A}-(\alpha \cdot \mathrm{TBC})] \lll \mathrm{k}_{3}$ for the Robinson and Rapoport model (12), the peroxidase test requires $\mathrm{kp} \cdot[\mathrm{HRP}]$ $\ll \mathrm{k}_{2} \cdot[\mathrm{A}-(\alpha \cdot \mathrm{TBC})]$ if $\mathrm{B}_{\mathrm{fss}}$ is to approximate $\mathrm{B}_{\mathrm{feq}}(19)$. When $\mathrm{B}_{\mathrm{f} 2}>$ $1.05 \cdot \mathrm{B}_{\mathrm{f} 1}(5 \%$ is the error of the method) the required condition is not met and $\mathrm{B}_{\mathrm{eq}}$ is underestimated at both peroxidase concentrations by at least $5 \%$. Fortunately, the reciprocal of equation 7 provides a linear relationship between $1 / \mathrm{B}_{\mathrm{fss}}$ and [HRP] with the reciprocal of the $\mathrm{y}$ intercept providing $\mathrm{B}_{\mathrm{fss}}$ when $[\mathrm{HRP}]$ is zero, i.e., $\mathrm{B}_{\text {feq }}$ :

$$
1 / B_{f s s}=\frac{k_{p} \cdot[H R P]}{k_{1} \cdot \alpha \cdot T B C}+\frac{k_{2} \cdot[A-(\alpha \cdot T B C)]}{k_{1} \cdot \alpha \cdot T B C}=\frac{k_{p} \cdot[H R P]}{k_{1} \cdot \alpha \cdot T B C}+\frac{1}{B_{e q}}
$$

In this circumstance (and assuming $\alpha=1$ ), $\mathrm{k}_{1}$ can be obtained from the slope of equation 8 as $\mathrm{k}_{1}=\mathrm{k}_{\mathrm{p}} /(\mathrm{TBC} \cdot$ slope $)$, following which $\mathrm{k}_{2}$ can be obtained from the intercept as $\mathrm{k}_{2}=$ intercept $\cdot \mathrm{k}_{1} \cdot \mathrm{TBC} /(\mathrm{A}-\mathrm{TBC})(19)$. The mean $\mathrm{k}_{\mathrm{p}}$ for the stock peroxidase was $18 / \mathrm{s}$ per $\mu \mathrm{mol} / \mathrm{L}$ of $\operatorname{HRP}(\mathrm{SD} 1.1, n=16$ ).

An important caveat is that sample dilution alters bilirubin-albumin binding in plasma as well as purified albumin solutions $(20,21) . \mathrm{B}_{\text {feq }}$ at the 42 -fold sample dilution used in this study is likely to be much smaller than $\mathrm{B}_{\text {feq }}$ in the undiluted sample, but it has been shown that the levels do correlate linearly (22). Dilution appears to primarily affect $k_{2}$ rather than $k_{1}(23)$ and because $B_{f}$ is usually 2-to 5-fold lower at a 42-fold sample dilution (20,21), the impact of an order of magnitude increasein $\mathrm{B}_{\text {feq }}$ or decrease ink $\mathrm{z}_{2}$ on the results was taken into consideration when analyzing the data.

Calculation of $\mathrm{BBU}$ by equation 6 (the Robinson and Rapoport model). $\mathrm{BBU}$ was calculated for each sample using equation 6 . E was calculated from 
equation 9 , which is derived from the general equation for $\mathrm{E}$ just above it using $\alpha=1$, the measured $\mathrm{k}_{1}$ for the sample, and the values provided by Robinson and Rapoport of $0.08 / \mathrm{s}$ for $\mathrm{k}_{3}$ and $1.75 \mathrm{~s}$ for the mean brain capillary transit time $(\tau)(13)$ :

$$
\begin{aligned}
& E=\left(1-e^{-k_{3} \tau}\right)-\alpha\left[\frac{k_{3}}{k_{3}-k_{1}}\left(e^{-k_{1} \tau}-e^{-k_{3} \tau}\right)\right] \\
& E=.131-\left[\frac{0.08}{0.08-k_{1}}\left(e^{-k_{l} \cdot 1.75}-0.869\right)\right]
\end{aligned}
$$

Inserting $\mathrm{E}$ for the sample along with the measured TBC and a cerebral blood flow of $0.5 \mathrm{~mL} / \mathrm{s} / \mathrm{kg}$ obtained from the reported blood flow rate $0.5 \mathrm{~mL} / \mathrm{s} / 100$ $\mathrm{g}$ of brain (24) and a brain weight of $100 \mathrm{~g} / \mathrm{kg}$ (25) into equation 6 provided $\mathrm{BBU}$ according to the Robinson and Rapoport model as:

$$
\mathrm{BBU}=0.5 \mathrm{~mL} / \mathrm{s} / \mathrm{kg} \cdot \mathrm{TBC} \cdot \mathrm{E}
$$

Calculation of $\boldsymbol{B B U}$ using $\boldsymbol{B}_{f}$. If $\mathrm{BBU}$ is determined primarily by $\mathrm{B}_{\mathrm{f}}$, the instantaneous decrease in $\mathrm{B}_{\text {feq }}$ as blood enters the brain capillaries is given by:

$$
\frac{d B_{f e q}}{d t}=-k_{3} \cdot B_{f e q}
$$

Integrating equation 11 between the time that blood enters the capillary $(\mathrm{t}=0)$ and the time it exits the capillary $(\tau)$ during which $\mathrm{B}_{\text {feq }}$ falls to $\mathrm{B}_{\mathrm{fss}}$, one obtains:

$$
\int_{B_{f e q}}^{B_{f s s}} \frac{d B_{f}}{B_{f}}=-\int_{0}^{\tau} k_{3} \cdot d t=\ln \left(\frac{B_{f s s}}{B_{e q}}\right)=-k_{3} \cdot \tau
$$

The fraction of $\mathrm{B}_{\text {feq }}$ removed on passing through the brain capillaries, comparable to $\mathrm{E}$ in equation 10, is:

Fraction of $\mathrm{B}_{\mathrm{f}}$ extracted $=1-\frac{B_{f s s}}{B_{e q}}=1-e^{-k_{3} \cdot \tau}$, and therefore

$$
\mathrm{BBU}=0.5 \mathrm{~mL} / \mathrm{kg} \cdot \mathrm{B}_{\mathrm{feq}} \cdot\left(1-e^{-k_{3} \tau}\right)
$$

If $\mathrm{k}_{3}=0.08 / \mathrm{s}$ and $\tau=1.75 \mathrm{~s}, \mathrm{BBU}$ is given as:

$$
\mathrm{BBU}=0.5 \mathrm{~mL} / \mathrm{s} / \mathrm{kg} \cdot \mathrm{B}_{\mathrm{feq}} \cdot 0.131
$$

\section{RESULTS}

A total of $293 \mathrm{~B}_{\mathrm{f}}$ measurements were made in a population of 256 jaundiced newborns. Of these, 198 samples from 185 newborns had $\mathrm{B}_{\mathrm{f} 2}$ levels that exceeded $\mathrm{B}_{\mathrm{f} 1}$ by $5 \%$ or more (mean $17 \%$, SD $11 \%$, range 6-69\%). The mean birth weight and gestational age were $2401 \mathrm{~g}(\mathrm{SD}=1103$, range 406$4483, n=185$ ) and $34 \mathrm{wk}$ (SD 5, range 24-42 $\mathrm{wk}, n=185)$, respectively. The mean TBC and $\mathrm{B}_{\mathrm{f}}$ were $15.3 \mathrm{mg} / \mathrm{dL}$ (SD 7.0, range 2.8-34.2) and $1.12 \mu \mathrm{g} / \mathrm{dL}$ (SD 0.89, range 0.11-7.63), respectively. The mean $\mathrm{B}_{\mathrm{f} 1}$ and $\mathrm{B}_{\mathrm{f} 2}$ were $0.77 \mu \mathrm{g} / \mathrm{dL}(\mathrm{SD} 0.55$, range $0.09-3.83, n=198$ ) and $0.90 \mu \mathrm{g} / \mathrm{dL}$, SD 0.66, range $0.10-5.1)$, respectively. Albumin was measured in 181 samples $(91 \%)$, and the mean was $3.4 \mathrm{~g} / \mathrm{dL}$ (SD 0.7, range 1.04.7). The various constants are given according to birth weight in Table 1.

Is $\boldsymbol{k}_{2} \ll \boldsymbol{k}_{3}$ ? The mean $\mathrm{k}_{2}$ (Table 1) was $8.9 \mathrm{~L} / \mu \mathrm{mol} / \mathrm{s}$, which is numerically about 100 times greater than $k_{3}(0.08)$. Even if undiluted plasma has a mean $\mathrm{k}_{2}$ two orders of magnitude less $(0.089 \mathrm{~L} / \mu \mathrm{mol} / \mathrm{s})$, the assumption required by the Robinson and Rapoport model that $\mathrm{k}_{2} \cdot[\mathrm{A}-(\alpha \cdot \mathrm{TBC})] \ll$ $\mathrm{k}_{3}$ will not be valid. Review of the literature provided no evidence that $\mathrm{k}_{3}$ might be substantially larger than $0.08 / \mathrm{s}$ (26), and assuming $\mathrm{A}$ underestimates the total concentration of bilirubin binding sites only reinforces the conclusion that the assumption is not valid.

Is $\boldsymbol{B} \boldsymbol{B} \boldsymbol{U} \leq \mathbf{0 . 0 0 5} \boldsymbol{\mu g} / \mathbf{k g} / \mathbf{s}$ ? The mean $\mathrm{k}_{1}$ (Table 1) was $0.093 / \mathrm{s}$. E calculated by equation 9 ranged from 0.001 to 0.036 (mean 0.010 , SD 0.006), indicating that as little as $0.1 \%$ to as much as $3.6 \%$ of the TBC according to the model would be extracted as blood passed through the cerebral capillaries.

The mean BBU calculated using equation 10 (Robinson and Rapoport model) was $0.72 \mu \mathrm{g} / \mathrm{kg} / \mathrm{s}$ (SD 0.52, range 0.057-2.7), with the calculated BBU exceeding the reported bilirubin production rate of $0.1 \mu \mathrm{g} / \mathrm{kg} / \mathrm{s}$ in 193 of 198 samples $(97 \%)$. Assuming BBU equals the bilirubin production rate (it could not proceed any faster), about $25 \%$ of the miscible bilirubin pool rather than the reported $<1 \%$ should be found in the brain.

The mean BBU as a function of $\mathrm{B}_{\mathrm{f}}$ (equation 15) was $0.00073 \mu \mathrm{g} / \mathrm{kg} / \mathrm{s}$ (SD 0.00058, range 0.000073-0.0050), which

\begin{tabular}{|c|c|c|c|c|c|}
\hline & $\begin{array}{c}\text { All Groups } \\
\mathrm{k}_{1} n=198 \\
\mathrm{k}_{2} n=181 \\
\mathrm{k}_{2} / \mathrm{k}_{1} n=181\end{array}$ & $\begin{array}{c}>2500 \mathrm{~g} \\
\mathrm{k}_{1} n=101 \\
\mathrm{k}_{2} n=85 \\
\mathrm{k}_{2} / \mathrm{k}_{1} n=85\end{array}$ & $\begin{array}{c}1501-2500 \mathrm{~g} \\
\mathrm{k}_{1} n=31 \\
\mathrm{k}_{2} n=30 \\
\mathrm{k}_{2} / \mathrm{k}_{1} n=30\end{array}$ & $\begin{array}{c}1001-1500 \mathrm{~g} \\
\mathrm{k}_{1} n=29 \\
\mathrm{k}_{2} n=32 \\
\mathrm{k}_{2} / \mathrm{k}_{1} n=32\end{array}$ & $\begin{array}{c}<1000 \mathrm{~g} \\
\mathrm{k}_{1} n=37 \\
\mathrm{k}_{2} n=34 \\
\mathrm{k}_{2} / \mathrm{k}_{1} n=34\end{array}$ \\
\hline \multicolumn{6}{|l|}{ Mean } \\
\hline $\mathrm{k}_{1} / \mathrm{s}$ & 0.093 & 0.076 & 0.095 & 0.130 & 0.110 \\
\hline $\mathrm{k}_{2} \mathrm{~L} / \mu \mathrm{mol} / \mathrm{s}$ & 8.9 & 12.4 & 7.0 & 6.4 & 4.3 \\
\hline $\mathrm{k}_{2} / \mathrm{k}_{1} \mathrm{~L} / \mu \mathrm{mol}$ & 93 & 130 & 73 & 64 & 46 \\
\hline \multicolumn{6}{|l|}{ SD } \\
\hline $\mathrm{k}_{1} / \mathrm{s}$ & 0.068 & 0.047 & 0.057 & 0.110 & 0.077 \\
\hline $\mathrm{k}_{2} \mathrm{~L} / \mu \mathrm{mol} / \mathrm{s}$ & 25.6 & 36.8 & 4.9 & 4.7 & 3.4 \\
\hline $\mathrm{k}_{2} / \mathrm{k}_{1} \mathrm{~L} / \mu \mathrm{mol}$ & 147 & 20 & 27 & 32 & 26 \\
\hline \multicolumn{6}{|l|}{ Range } \\
\hline $\mathrm{k}_{1} / \mathrm{s}$ & $0.008-0.390$ & $0.008-0.260$ & $0.020-0.270$ & $0.017-0.390$ & $0.019-0.340$ \\
\hline $\mathrm{k}_{2} \mathrm{~L} / \mu \mathrm{mol} / \mathrm{s}$ & $0.43-330.7$ & $0.6-330.7$ & $1.2-19.1$ & $1.1-24.1$ & $0.4-14.1$ \\
\hline $\mathrm{k}_{2} / \mathrm{k}_{1} \mathrm{~L} / \mu \mathrm{mol}$ & $15-1602$ & $27-1602$ & $15-125$ & $23-163$ & $15-107$ \\
\hline
\end{tabular}
is $0.73 \%$ of the bilirubin production rate and much more in line with the anticipated BBU of $\leq 0.005 \mu \mathrm{g} / \mathrm{kg} / \mathrm{s}$. Interestingly, if $\mathrm{B}_{\mathrm{f}}$ is actually an order of magnitude higher in undiluted plasma $(20-22)$, BBU would be about $7 \%$ of the bilirubin production

Table 1. Statistics for bilirubin-albumin dissociation and association rate constants $\left(k_{1}\right.$ and $k_{2}$, respectively) and $k_{2} / k_{1}($ the equilibrium association constant) in jaundiced newborns by birth weight

There were 17 samples in which $\mathrm{k}_{2}$ and $\mathrm{k}_{2} / \mathrm{k}_{1}$ could not be calculated because albumin was not measured. 
rate and about $1.8 \%$ of the miscible bilirubin pool would be expected to reside in the brain. This is still very close to the value expected, and BBU by the total bilirubin model would either be the same or increase depending on the degree to which $\mathrm{k}_{1}$ is affected by dilution $\left(\mathrm{k}_{2} / \mathrm{k}_{1}\right.$ decreases as $\mathrm{B}_{\mathrm{f}}$ increases requiring some combination of a decrease in $\mathrm{k}_{2}$ and/or increase in $\mathrm{k}_{1}$ ). Even if $\mathrm{k}_{2}$ is an order of magnitude smaller, it still is 10-fold higher than $\mathrm{k}_{3}$.

\section{DISCUSSION}

Our results show that the Robinson and Rapoport mathematical model predicting that BBU will be largely a function of the TBC at TBC levels below $27 \mathrm{mg} / \mathrm{dL}$ is invalid when measured values for $\mathrm{TBC}$ and the bilirubin-albumin dissociation rate constant $\left(\mathrm{k}_{1}\right)$ along with constants from the literature for brain bilirubin blood flow, capillary transit time $(\tau)$, and brain bilirubin uptake $\left(\mathrm{k}_{3}\right)$ are applied to the model. $\mathrm{B}_{\text {feq }}$ when $\mathrm{k}_{3}=$ $0.08 / \mathrm{s}$ and $\tau=1.75 \mathrm{~s}$ will not fall sufficiently in the cerebral capillaries to meet the assumptions required for equation 5 to be operative. For the Robinson and Rapoport model to be operative, the expression $\mathrm{e}^{-\mathrm{k}_{3} \cdot \tau}$ in equation 13 must be nearly zero, indicating that virtually $100 \%$ of the $B_{f}$ is taken up within a few milliseconds of the blood entering the capillary. This requires $-\mathrm{k}_{3} \cdot \tau$ to be much greater than previously reported. Since $\tau$ is unlikely significantly greater, $\mathrm{k}_{3}$ in humans would need to be orders of magnitude larger than the values reported in animals. Even assuming $\mathrm{k}_{3}=80 / \mathrm{s}$ (1000-fold higher than the value in animals), at the mean $\mathrm{k}_{2}$ of our study (8.9 $\mathrm{L} / \mu \mathrm{mol} / \mathrm{s})$, a TBC of $10 \mathrm{mg} / \mathrm{dL}(171 \mu \mathrm{M})$, and the mean study albumin of $3.4 \mathrm{~g} / \mathrm{dL}(514 \mu \mathrm{M}), \mathrm{k}_{2} \cdot[\mathrm{A}-(\alpha \cdot \mathrm{TBC})]$ in equation $4=3052.7 / \mathrm{s}$ versus a $\mathrm{k}_{3}=80 / \mathrm{s}$, which clearly invalidates the assumption in equation 4 required by the Robinson and Rapoport model that $\mathrm{k}_{2} \cdot[\mathrm{A}-(\alpha \cdot \mathrm{TBC})]$ is so small relative to $\mathrm{k}_{3}$ that it can be ignored giving equation 5 . Thus, all the plasma mass action variables determining BBU must be operative (TBC, $\mathrm{A}, \mathrm{k}_{1}$, and $\mathrm{k}_{2}$ ), and because the fraction of bilirubin extracted during brain capillary transit is constant (equation 15), the overall amount of bilirubin taken up by the brain during capillary transit will be a function of $\mathrm{B}_{\mathrm{feq}}$.

Our bilirubin-albumin binding data were from a diverse population of jaundiced newborns to provide a wide range of binding variables for the models, and because it was not possible to measure the bilirubin production rate, bilirubin pool distribution, and cerebral blood flow for each newborn, we applied our best estimate of each variable to the population. Variation in cerebral blood flow would apply to both models equally (equations 10 and 14) and not change the results. Because BBU by the Robinson and Rapoport model is 1000fold greater than that by the $\mathrm{B}_{\mathrm{f}}$ model, the BBU as a percentage of bilirubin production rate would not change greatly with variation in bilirubin production (even at triple the bilirubin production rate as occurs in hemolysis (14) BBU by the Robinson and Rapoport model still exceeds the production rate and $\mathrm{BBU}$ by the $\mathrm{B}_{\mathrm{f}}$ model remains below $1 \%$ of the production rate). The percentage of the miscible bilirubin pool residing in the brain could also be in error by an order of magnitude ( $10 \%$ versus $<1 \%$ ) and BBU by the Robinson and Rapoport model would still far exceed the BBU predicted.

Considering the above, it is not unexpected that the BBU calculated according to the model (equation 10) was far too high relative to the bilirubin production rate for the model to be considered an accurate representation of $\mathrm{BBU}$. BBU rates calculated using $B_{f}$ as the operative plasma species (equation 15), however, are within the range expected assuming the reports that $<1 \%$ of the miscible bilirubin pool distributes in the brain are reasonably accurate and applicable to human newborns $(15,16)$. Although sample dilution may systematically alter the binding variables (20-23), even when order of magnitude errors in the variables are invoked, the Robinson and Rapoport model still fails.

It is ironic that were the model correct, the variability in $\mathrm{k}_{1}$ (Table 1) would still require routine measurement of bilirubinalbumin binding, but the desired result would usually be $\mathrm{k}_{1}$ (to calculate $\mathrm{E}$ ) rather than $\mathrm{B}_{\mathrm{f}}$. This paradoxical "inconstancy" of constants (Table 1) is a subtle but important reminder that there is considerable variability in plasma bilirubin binding in jaundiced newborns. If not, $\mathrm{B}_{\mathrm{f}}$ could be calculated from the TBC and albumin, assuming albumin binds most of the bilirubin in plasma (7) We found a $73 \%$ coefficient of variation in $\mathrm{k}_{1}$ and a $158 \%$ variation in the equilibrium association constant $\left(\mathrm{k}_{2} /\right.$ $\mathrm{k}_{1}$ ). Cashore (27), using the peroxidase test and a single peroxidase concentration, has reported a $40 \%$ coefficient of variation for $\mathrm{k}_{2} / \mathrm{k}_{1}$ in well term newborns. The reasons for this variability are mostly unknown, but albumin dimerization and polymorphism (28) and small competing molecules generated during illness (29) may contribute. Variability in the nonplasma factors that can alter individual susceptibility to bilirubin toxicity, including interindividual variability in BBU, also deserve more study (30).

The Robinson and Rapoport model cannot be used as evidence supporting the use of the TBC alone when evaluating jaundiced newborns in any circumstances. Our data suggest that even if significant non-albumin binding of bilirubin in plasma occurs, $\mathrm{B}_{\mathrm{f}}$ as measured by the peroxidase test provides rates of $\mathrm{BBU}$ consistent with the reported bilirubin production rate and miscible bilirubin pool distribution. Continued investigation of the usefulness of $B_{f}$ measured in minimally diluted plasma (22) as an adjunct in the evaluation of newborn jaundice seems warranted.

\section{REFERENCES}

1. Diamond I, Schmid R 1966 Experimental bilirubin encephalopathy. The mode of entry of bilirubin $-{ }^{14} \mathrm{C}$ into the central nervous system. J Clin Invest 45:678-689

2. Ostrow JD, Pascolo L, Shapiro SM, Tiribelli C 2003 New concepts in bilirubin encephalopathy. Eur J Clin Invest 33.988-997

3. Ahlfors CE, Herbsman O 2003 Unbound bilirubin in a term newborn with kernicterus. Pediatrics 111:1110-1112

4. American Academy of Pediatrics 2004 Clinical Practice Guideline. Subcommittee on Hyperbilirubinemia. Pediatrics 114:297-316

5. Blackmon LR, Fanaroff AA, Raju TN 2004 National Institute of Child Health and Human Development. Research on prevention of bilirubin-induced brain injury and kernicterus: National Institute of Child Health and Human Development conference and executive summary. Pediatrics 114: 229-233

6. Stevenson DK, Wong RJ, Vreman HJ, McDonagh AF, Maisels MJ, Lightner DA 2004 NICHD Conference on Kernicterus: research on prevention of bilirubin-induced brain injury and kernicterus: bench-to-bedside-diagnostic methods and prevention and treatment strategies. J Perinatol 24:521-525

7. Goessling W, Zucker SD 2000 Role of apolipoprotein D in the transport of bilirubin in plasma. Am J Gastrointest Liver Physiol 279:G356-G365 
8. Nakamura H, Yonetani M, Uetani Y, Funato M, Lee Y 1992 Determination of serum unbound bilirubin for prediction of kernicterus in low birthweight infants. Acta Paediatr Jpn 34:642-647

9. Funato M, Tamai H, Shimada S, Nakamura H 1994 Vigintiphobia, unbound bilirubin, and auditory brainstem responses. Pediatrics 93:50-53

10. Amin SB, Ahlfors C, Orlando MS, Dalzell LE, Merle KS, Guillet R 2001 Bilirubin and serial auditory brainstem responses in premature infants. Pediatrics 107: 664-670

11. Ahlfors CE, Wennberg RP 2004 Bilirubin-albumin binding and neonatal jaundice. Semin Perinatol 28:334-339

12. Robinson PJ, Rapoport SI 1986 Kinetics of protein binding determine rates of uptake of drugs by brain. Am J Physiol 251:R1212-R1220

13. Robinson PJ, Rapoport SI 1987 Binding effect of albumin on uptake of bilirubin by brain. Pediatrics 79:553-558

14. Maisels MJ, Pathak A, Nelson NM, Nathan DG, Smith CA 1971 Endogenous production of carbon monoxide in normal and erythroblastotic newborn infants. J Clin Invest 50:1-8

15. Schmid R, Hammaker L 1963 Metabolism and disposition of $\mathrm{C}^{14}$-bilirubin in congenital nonhemolytic jaundice. J Clin Invest 42:1720-1734

16. Davis DR, Yeary RA 1975 Effect of sulfadimethoxine on tissue distribution of $\left[{ }^{14} \mathrm{C}\right.$ bilirubin in the newborn and adult hyperbilirubinemic Gunn rate. Pediatr Res 9:846850

17. Shimabuku R, Nakamura H 1982 Total and unbound bilirubin determined using an automated peroxidase micromethod. Kobe J Med Sci 28:91-104

18. Jacobsen J, Wennberg RP 1974 Determination of unbound bilirubin in the serum of newborns. Clin Chem 20:783

19. Faerch T, Jacobsen J 1975 Determination of the association and dissociation rate constants for bilirubin-bovine serum albumin. Arch Biochem Biophys 168:351-357
20. Ahlfors CE 1981 Effect of serum dilution on apparent unbound bilirubin concentration as measured by the peroxidase method. Clin Chem 27:692-696

21. Weisiger RA, Ostrow JD, Koehler RK, Webster CC, Mukerjee P, Pascolo L, Tiribell C 2001 Affinity of human serum albumin for bilirubin varies with albumin concentrations and buffer composition: results of a novel ultrafiltration method. J Biol Chem 276:29953-29960

22. Ahlfors CE 2000 Measurement of plasma unbound unconjugated bilirubin. Anal Biochem 279:130-135

23. Ahlfors CE, DiBiasio-Erwin D 1986 Rate constants for dissociation of bilirubin from its binding sites in neonatal (cord) and adult sera. J Pediatr 108:295-298

24. Wintermark M, Lepori D, Cotting J, Roulet E, van Melle G, Meuli R, Maeder P, Regli L, Verdun FR, Deonna T, Schnyder P, Gudinchet F 2004 Brain perfusion in children: evolution with age assessed by quantitative perfusion computed tomography. Pediatrics 113:1642-1652

25. Jordaan HV 1976 Newborn brain: body weight ratios. Am J Phys Anthropol 44:279-284

26. Ives NK, Gardiner RM 1990 Blood-brain barrier permeability to bilirubin in the rat studied using intracarotid bolus injection and in situ brain perfusion techniques. Pediatr Res 27:436-441

27. Cashore WJ 1980 Free bilirubin concentration and bilirubin-binding affinity in term and preterm infants. J Pediatr 96:521-527

28. Lorey FW, Ahlfors CE, Smith DG, Neel JV 1984 Bilirubin binding by variant albumins in Yanomama Indians. Am J Hum Genet 36:1112-1120

29. Gulyassy PF, Bottini AT, Jarrad EA, Stanfel LA 1983 Isolation and inhibitors of ligand:albumin-binding from uremic body fluids and normal urine. Kidney Int Suppl 16:S238-S242

30. Hansen TW 2001 Bilirubin brain toxicity. J Perinatol 21:S48-S51 